Portland State University

PDXScholar

Engineering and Technology Management

Faculty Publications and Presentations

$12-1-2017$

\title{
Monitoring and Anticipating the Convergence of Lighting Control Strategies
}

\author{
Nina Chaichi \\ Portland State University \\ Tugrul Unsal Daim \\ Portland State University, tugrul@etm.pdx.edu
}

Follow this and additional works at: https://pdxscholar.library.pdx.edu/etm_fac

Part of the Engineering Commons

Let us know how access to this document benefits you.

\section{Citation Details}

N. Chaichi and T. Daim, "Monitoring and Anticipating the Convergence of Lighting Control Strategies," 2017 Portland International Conference on Management of Engineering and Technology (PICMET), Portland, OR, 2017, pp. 1-7.

This Article is brought to you for free and open access. It has been accepted for inclusion in Engineering and Technology Management Faculty Publications and Presentations by an authorized administrator of PDXScholar. Please contact us if we can make this document more accessible: pdxscholar@pdx.edu. 


\title{
Monitoring and Anticipating the Convergence of Lighting Control Strategies
}

\author{
Nina Chaichi, Tugrul Daim \\ Engineering and Technology Management, Portland State University, Portland, USA
}

\begin{abstract}
IPC co-classification in conjunction with cross impact analysis has been used to identify technology convergence and its strength over specific period of time. In this study, we tried to monitor the convergence of lighting control strategies which yields energy efficiency from 2009 to 2013. Also, we tried to anticipate the trend of impacts for near future. We take new approach to utilize detailed information including rate of change of co-classified patents, number of patents in each class, and convergence strength between two classes over time and build possible scenarios to anticipate the convergence trend. In our new approach, convergence strength rate of change is considered along side with two other parameters to understand the reason of rise or decline in convergence strength and possibility of its change in the future. With recent trends considering lighting as a system rather than group of components, our approach would help to anticipate the convergence trends of the controlling strategies including time control, presence control, illuminance control and so forth as a controlling system.
\end{abstract}

\section{INTRODUCTION}

Technology convergence is useful to have a better understanding of technology trends. Convergence is defined as "a blurring of boundaries between at least two hitherto disjoint areas of science, technology, markets, or industries" [1]. Convergence can be categorized into knowledge convergence, technology convergence, application convergence, and industry convergence, where starts with knowledge convergence and lead into the next convergence category which ends with industry convergence [2]. There are successful case where patent data used to identify technology and industry convergence [1], [3]-[7]. Though, not all the inventions filed as patents in order to prevent knowledge spill over to competitors which is the biggest limitation of using patent data for patent analysis [8]. Co-classification analysis of patent data in combination with cross-impact analysis has been widely used methodology to monitor technology convergence [3]-[7]. Though cross-impact analysis is good to illustrate the average influence of each class on others, it does not provide any information on increasing or decreasing nature of the convergence. Analyzing the trend of impact over time overcomes the shortcoming of cross-impact analysis. Trend impact analysis monitors the convergence strength as well as increasing and decreasing trend over time to predict the future. As it sounds, there are two problems associated with trend impact analysis - first, it needs to hold increasing and decreasing trend over time, and second, it needs to be done over a long period of time to produce meaningful result - in some cases [4].
In recent years, lighting industry undergone fundamental changes influenced by the rapid improvement of LED technologies. Figure $2 b$. is a proof for this rapid changes, as the number of the patents for three controlling techniques and strategy sharply increased. One of the recent activities is to develop lighting system by converging various technologies [9], [10]. Though use of trend impact analysis sounds appropriate to study the intended convergence, we faced with two problems mentioned earlier. In order to capture these changes, very recent and available patent data needed to be considered which shorten the period of study. Besides, in our case, convergence trend does not hold steady increasing and decreasing pattern. To overcome these issues, we take a new approach to using scenario analysis to project convergence trend over a longer period of time based on available patent data over a short period of time. This new approach has been used to analyze convergence to understand which controlling strategies are developed together as coordinated controlling system to save energy.

Lighting can contribute into energy saving in two ways, more efficient light source such as LEDs and using automatic control to provide right amount of light in right time and right place [11], [12]. The general controlling strategies to provide energy efficiency includes:

1. occupancy sensing to provide right amount of light according to occupancy [11], [13]-[15].

2. scheduling to have right amount of light based on schedule [11].

3. tuning to provide right amount of light according to user needs [11], [15], [16].

4. daylight harvesting to change light output based on available natural light [11], [15].

5. demand response to change light output according to third party needs [11].

6. adaptive compensation to change the light level during the night and day [11].

Each controlling strategies will yield different amount of saving [15], besides the type of light source would increase or decrease the benefit of controlling, for instance, using LED will reduce the benefit of controlling system [17].

The objectives of this study are: (i) which controlling strategy are received more attention and developed faster? (ii) which two strategies are likely developed together as coordinated system? (iii) anticipate the trend of impact strategies have on each other? The rest of this paper is 
organized as follows. Section II explains the process of acquiring relevant patent data. In section III, methodology used to monitor and anticipate the cross-impact analysis has been elaborated. Section IV and V discuss the result of monitoring and anticipating convergence trend, and in last section we conclude the results.

\section{DATA}

There are several classifications for patent including united states patent classification (USPC), International patent classification (IPC), cooperative patent classification (CPC), and so forth. CPC is the result of recent effort's of European patent office (EPO) and united states patent office (USPTO) to unify and harmonize patent classification [18]. CPC has been combined the best classification of EPO and USPTO, and besides, introduced new section (Y) that covers new technological developments and cross-sectional technologies spanning over several sections of the IPC [18], [19]. In this study, we used CPC classification to conduct patent analysis. Sub-groups related to lighting controls have been found in $\mathrm{H}$, $\mathrm{F}$, and $\mathrm{Y}$ sections.

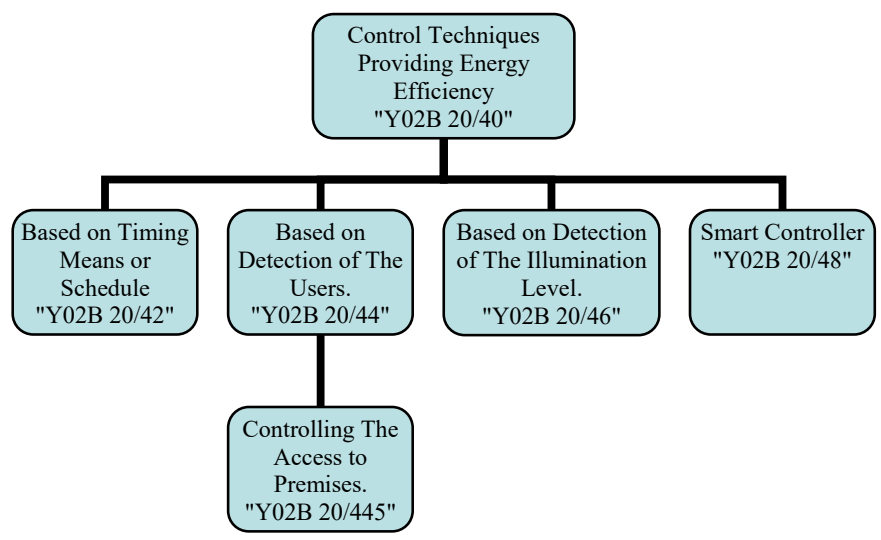

Figure 1 - Lighting controls yielding energy efficiency CPC hierarchy
This paper tends to monitor and predict of convergence of lighting control which works as a coordinated system and yields energy efficiency. So, the suitable CPC main group aligned with the purpose of paper is Y02B 20/00 that classifies energy efficient lighting technologies. In this group, the subgroups related to lighting controls are Y02B 20/40 - control techniques providing energy efficiency, Y02B 20/42 control techniques providing energy efficiency based on timing means or schedule, Y02B 20/44 - control techniques providing energy efficiency based detection of the users, Y02B 20/445 - control techniques providing energy efficiency based on controlling the access to premises, Y02B 20/46 - control techniques providing energy efficiency based on detection of the illumination level, Y02B 20/48 - control techniques providing energy efficiency with smart controller. These CPCs can be mapped to general controlling strategy mentioned in introduction. It can say the equivalents are as follows - Y02B 20/42 equivalent of strategy 2, Y02B 20/44 and Y02B 20/445 equivalent of strategy 1, Y02B 20/46 equivalent of strategy 4, Y02B 20/48 equivalent of strategy 3, 5, and 6 . Based on the description of Y02B 20/40 patents refer to techniques that control the light source rather than controlling strategy.

We used EPO's database which includes worldwide patents - more than 80 patent office data [18] - to acquire our data. EPO developed SQL based tool called PATSTAT [18] that allows to extract relevant patent data from their relational database (please see appendix to find code used to extract data). Goal of this paper to analyze the recent trend of patents, so we gathered patents which approved at 2009 and later. However, we can't go later than 2013, since on average three years takes to patent get approved. The sharp decrease shown in figure $2 \mathrm{~b}$. is an indicator of approval period, and the fact that patents filled in 2014 and later are still under review.

TABLE 1 - CPC SECTIONS, MAIN GROUPS, AND SUB GROUPS RELATED TO LIGHTING CONTROL SYSTEM [19].

\begin{tabular}{|c|c|c|c|}
\hline Section & Main Group & Main Group Description & Sub Group \\
\hline $\mathrm{F}$ & $\mathrm{F} 21 \mathrm{~V} 23 / 00$ & $\begin{array}{l}\text { Arrangement of lighting in or } \\
\text { on lighting devices }\end{array}$ & $\begin{array}{l}\text { F21V23/0435, F21V23/0442, F21V23/045, F21V23/0457, F21V23/0464, F21V23/0471, } \\
\text { F21V23/0478, F21V23/0485, F21V23/0492 }\end{array}$ \\
\hline \multirow[t]{2}{*}{$\mathrm{H}$} & H05B 33/00 & $\begin{array}{l}\text { Electroluminescent light } \\
\text { sources }\end{array}$ & $\begin{array}{l}\text { H05B33/0812, H05B33/0815, H05B33/0824, H05B33/0827, H05B33/083, H05B33/0833, } \\
\text { H05B33/0836, H05B33/0839, H05B33/0842, H05B33/0845, H05B33/0848, H05B33/0851, } \\
\text { H05B33/0854, H05B33/0857, H05B33/086, H05B33/0863, H05B33/0866, H05B33/0869, } \\
\text { H05B33/0872 }\end{array}$ \\
\hline & H05B 37/00 & $\begin{array}{l}\text { Circuit arrangement for } \\
\text { electric light sources in } \\
\text { general }\end{array}$ & $\begin{array}{l}\text { H05B37/02, H05B37/0209, H05B37/0218, H05B37/0227, H05B37/0236, H05B37/0245, } \\
\text { H05B37/0254, H05B37/0263, H05B37/0272, H05B37/0282, H05B37/029 }\end{array}$ \\
\hline Y & Y02B 20/00 & $\begin{array}{l}\text { Energy efficient lighting } \\
\text { technologies }\end{array}$ & Y02B20/40, Y02B20/42, Y02B20/44, Y02B20/445, Y02B20/46, Y02B20/48 \\
\hline
\end{tabular}




\section{METHODOLOGY}

Classification codes are used to manage patent database effectively in different Patent classification system, similar classification would be assigned to the patents with similar characteristic to put them in the same subdirectory [20]. The group of classification codes would be assigned to the patent if it shows similar characteristic with different subcategories. Therefore, joint appearance of classification codes or coclassification could be considered as indicator of interrelation of technologies or technology convergence [21], [22].

The co-appearance frequency shows the strength of correlation between to classification. In convergence context, it is good to understand the impact each class has on each other. The cross impact analysis is useful method to calculate this impact. The CIA in patent analysis context between technology $\mathrm{A}$ and $\mathrm{B}$ defined as follow [23]:

$$
\begin{aligned}
& \operatorname{Impact}(A, B)=P(B \mid A)=N(A \cap B) / N(B) \\
& \operatorname{Impact}(B, A)=P(A \mid B)=N(A \cap B) / N(A)
\end{aligned}
$$

However, when it comes to anticipate the trend of technological convergence, it is helpful to study the convergence trend over time. It is argued in [21] that is hard to make sense of convergence trend over short period of time and when the convergence trend does not hold increasing or decreasing pattern. In this paper, we take new approach to ease this problem by using scenario analysis to anticipate the convergence trend for longer period based on data over short period of time. There are three factors are affecting the impact of technology A and B on each other. The growth and regress of technology A, B, and the intersection of technology A and B. The growth and regress of technology class shows if the class is in its emergence phase or getting mature. Formula 3 and 4 show how to calculate impact at given year $(\mathrm{t})$.

$$
\begin{aligned}
& \operatorname{Impact}(A, B) t=P(B \mid A) t=N(A \cap B) t / N(B) t \\
& \operatorname{Impact}(B, A) t=P(A \mid B) t=N(A \cap B) t / N(A) t
\end{aligned}
$$

Formula 5 and 6 illustrate show how to calculate the changes in impact in two adjacent year. This rate of change shown as $\mathrm{R}$ depends on the rate of change in number of patents in technology class (A or B) and the in number of patents belong in two technologies intersection.

$$
\begin{aligned}
& \mathrm{R}(\mathrm{A}, \mathrm{B})=\operatorname{Impact}(\mathrm{A}, \mathrm{B}) \mathrm{t}+1-\operatorname{Impact}(\mathrm{A}, \mathrm{B}) \mathrm{t} \\
& \mathrm{R}(\mathrm{B}, \mathrm{A})=\operatorname{Impact}(\mathrm{B}, \mathrm{A}) \mathrm{t}+1-\operatorname{Impact}(\mathrm{B}, \mathrm{A}) \mathrm{t}
\end{aligned}
$$

There are three outcome possibilities. The impact stays the same, increase, or decrease from one year to the other. In order to have same impact in two adjacent year, number of patents in intersection of two technologies and number of patents in technology class stays the same or increases and decreases with the same rate. The impact increases from one year to other, if the number of patents in intersection of two technologies increase while the number of patents in technology class decrease. Besides, If they both increasing, the number of patents in intersection of two technologies increases faster or if they decreasing, the number of patents in intersection of two technologies increases slower. Which cause decreasing pattern from one year to the other, is totally opposite of the increasing pattern.

\section{MONITORING CONVERGENCE}

All six CPC groups do not show the same pattern form 2009 to 2013. The number of patents in Y02B 20/40, Y02B 20/42, and Y02B 20/48 groups has increased during a chosen period. Controlling strategy based on timing and scheduling always has the highest number of patents. The number of patent for this group - Y02B 20/42 - has stayed almost the same from 2009 to 2011, however, it was doubled in two years and raised from 600 patents in 2011 to 1200 patents in 2013. Controlling techniques providing energy efficiency has the second highest number of patents most of the time. The number of patents for this group - Y02B 20/40 - intermittently went up and down, though, overall the number of patents have almost doubled from 2009 to 2011. The last strategy shows increasing patterns is smart controller. The patent number in this group - Y02B 20/48 - has consistently increased and almost tripled from 2009 to 2013, however, the rate of increase almost flattened in the last year.

On the other hand, the number of patents in Y02B 20/44, Y02B 20/445, and Y02B 20/46 has slightly decreased or stayed the same. Controlling strategy based on detection of users with or without controlling the access to promises and strategy based on the detection illumination level has the far less patents than the other three controlling strategies and techniques. These patent groups were growing or regressing with different rate, Figure 2a. illustrates the share of each CPC group among the granted patents for all of controlling strategies and techniques. The rate of change in the share of each group represents the relative speed of growth or regress in respect to other groups.

Timing and scheduling strategy had the highest share among them all. Its share showed slight decrease from 2009 to 2012 and stays around $40 \%$, while, suddenly increased in the last year to about $50 \%$. Controlling techniques had the most share after timing and scheduling strategy, though, its share intermittently went up and down and overall slightly decreased from 2009 to 2011. Smart controlling had the fastest growth and its share has consistently grown. Its share surpassed share of controlling techniques patent despite of slight decrease in respect to previous year. Share of other three strategies were always stayed below $10 \%$ and showed decreasing pattern. Their share of all three reached almost $1 \%$ in 2013. Share of each CPC groups can imply how much that group impacted by others, for instance, we can expect timing and scheduling has least impacted by others. However, the rate of change in patent share does not imply the same rate of change in impact that theologies have on each other since it has also effected by rate of change in the number of common patents in both $\mathrm{CPC}$ groups. 
TABLE 2 - OVERALL NUMBER OF PATENTS GRANTED FOR CPC GROUP AND THE NUMBER OF PATENTS BELONG TO INTERSECTION BETWEEN TWO CPC GROUPS.

\begin{tabular}{|c|c|c|c|c|c|c|}
\hline CPC & 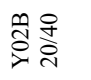 & 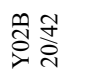 & 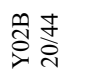 & 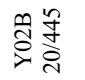 & 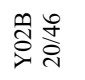 & 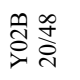 \\
\hline $\begin{array}{l}\text { Y02B } \\
20 / 40\end{array}$ & 2228 & & & & & \\
\hline $\begin{array}{l}\text { Y02B } \\
20 / 42\end{array}$ & 666 & 3673 & & & & \\
\hline $\begin{array}{l}\text { Y02B } \\
20 / 44\end{array}$ & 65 & 70 & 351 & & & \\
\hline $\begin{array}{c}\text { Y02B } \\
20 / 445\end{array}$ & 18 & 19 & 12 & 68 & & \\
\hline $\begin{array}{l}\text { Y02B } \\
20 / 46\end{array}$ & 48 & 68 & 18 & 2 & 424 & \\
\hline $\begin{array}{l}\text { Y02B } \\
20 / 48\end{array}$ & 495 & 562 & 57 & 11 & 30 & 1946 \\
\hline
\end{tabular}

TABLE 3 - THE RESULTS OF CROSS-IMPACT ANALYSIS

\begin{tabular}{|c|c|c|c|c|c|c|}
\hline CPC & $\begin{array}{l}\text { 帘 } \\
\text { 궁 }\end{array}$ & 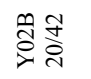 & 突 & 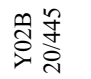 & 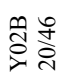 & 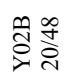 \\
\hline $\begin{array}{l}\text { Y02B } \\
20 / 40\end{array}$ & $100 \%$ & $18 \%$ & $19 \%$ & $26 \%$ & $11 \%$ & $25 \%$ \\
\hline $\begin{array}{l}\text { Y02B } \\
20 / 42\end{array}$ & $30 \%$ & $100 \%$ & $20 \%$ & $28 \%$ & $16 \%$ & $29 \%$ \\
\hline $\begin{array}{l}\text { Y02B } \\
20 / 44\end{array}$ & $3 \%$ & $2 \%$ & $100 \%$ & $18 \%$ & $4 \%$ & $3 \%$ \\
\hline $\begin{array}{c}\text { Y02B } \\
20 / 445\end{array}$ & $1 \%$ & $1 \%$ & $3 \%$ & $100 \%$ & $0 \%$ & $1 \%$ \\
\hline $\begin{array}{l}\text { Y02B } \\
20 / 46\end{array}$ & $2 \%$ & $2 \%$ & $5 \%$ & $3 \%$ & $100 \%$ & $2 \%$ \\
\hline $\begin{array}{l}\text { Y02B } \\
20 / 48\end{array}$ & $22 \%$ & $15 \%$ & $16 \%$ & $16 \%$ & $7 \%$ & $100 \%$ \\
\hline
\end{tabular}

Table 2. shows the number of patents have been granted in each CPC group and also the patents which was in common between two of them. For example, the number of patents have been granted in Y02B 20/40 group and belonged to both Y02B 20/40 and Y02B 20/42 groups from 2009 to 2013 is 2228 and 666 respectively. Table 3 . shows the strength of impact CPC groups on each others. Rows show how much impact the correspondent CPC had on others, while, columns show how much correspondent $\mathrm{CPC}$ has impacted by others. The result shows Y02B 20/46 has least impacted by others with one exception, though, we expected that Y02B 20/42 be in Y02B $20 / 46$ place due to its high share of patents. This implies that Y02B 20/46 place. Y02B 20/46 had least interaction with other controlling techniques and strategies and has been developed mostly in silo in comparison with others.

Cross-impact analysis results show that Y02B 20/42 had highest impact on others. It means developing any controlling techniques and strategies has highest chance to be accompanied by timing and scheduling strategy rather than others. Besides, Y02B 20/40, Y02B 20/42, Y02B 20/48 had almost sizable and comparable impact on each other. This impact could be almost equal in case of Y02B 20/40 and Y02B 20/48 where the impact of Y02B 20/40 on Y02B 20/48 was $25 \%$ and $22 \%$ the other way around. Or, at least half of the impact one of them had on the other one. For instance, Y02B 20/42 has impacted Y02B $20 / 40$ by $30 \%$ which was highest among all, though only has impacted by $18 \%$. Furthermore, Y02B 20/40, Y02B 20/42, Y02B 20/48 had high impact on Y02B 20/44 and Y02B 20/445 and also noticeable impact on Y02B 20/46, though, they have barely impacted by Y02B 20/44, Y02B 20/445, and Y02B 20/46.

Monitoring technology convergence over period of time only reflects the average impact. Though the year to year impact technologies have on each other swings around this average point. Figure 3. shows the change in impacts $\mathrm{CPC}$ groups had on Y02B 20/40. Though, the impact of Y02B 20/44, Y02B 20/445, and Y02B 20/46 on Y02B 20/40 had very low rate of change and stayed almost flat and under $5 \%$, the impact of Y02B 20/42 and Y02B 20/48 varied significantly via a given period. Impact of Y02B 20/42 went down from about $35 \%$ to around $25 \%$ and almost stayed the same for three years, however, it suddenly increased to $40 \%$ in the last year. Also, impact of Y02B 20/48 started at 15\% and went down to about $10 \%$ and then raised to about $35 \%$ with almost fixed slope in last three years.
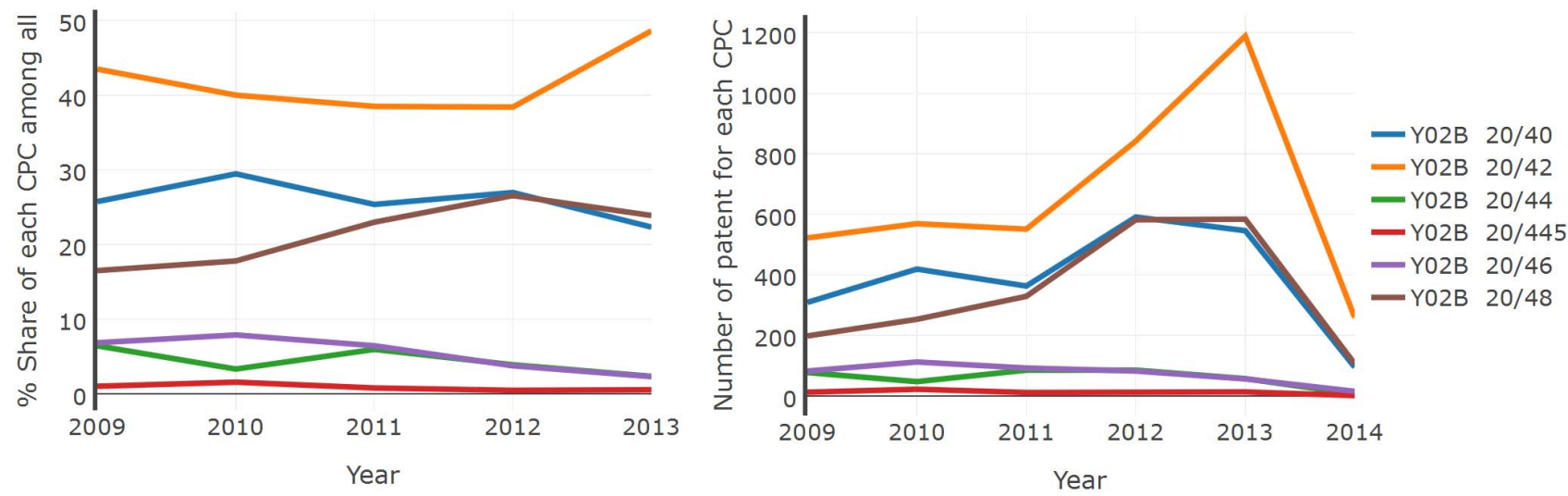

Figure 2 - (a) figure on the left shows the share of each CPC group among the patents granted in all the chosen CPC groups. (b) figure on the right shows the number of patents granted for each CPC group 2009-2013. 


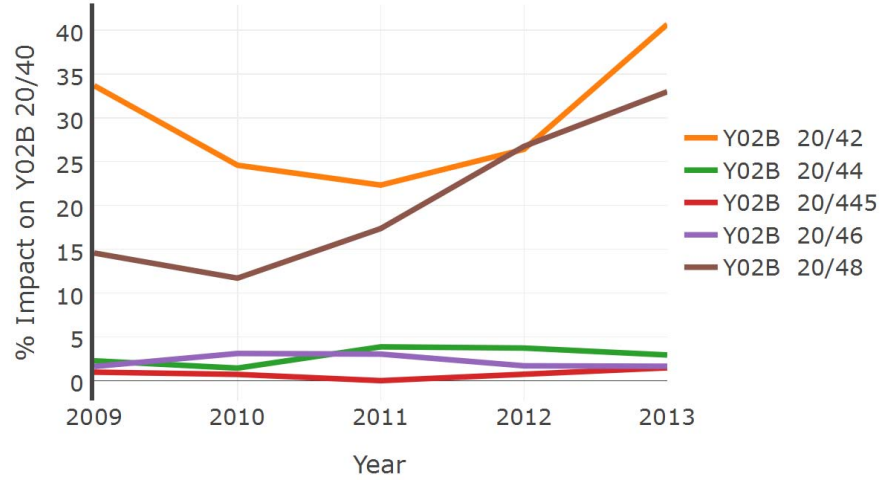

Figure 3 - Impacts on Y02B 20/40, 2009-2013.

In order to anticipate the trend of convergence, systematic approach required to analyze the changes of impact over time with considering the source of change. In next section, we discuss the systematic approach we proposed to predict the convergence.

\section{Predicting Convergence}

As discussed in methodology section, cross-impact analysis results depends on three factors - number of patents in technology A, B, and their intersection. The rate of change in any of these three factors would affect the trend of impact results that they have on each other.

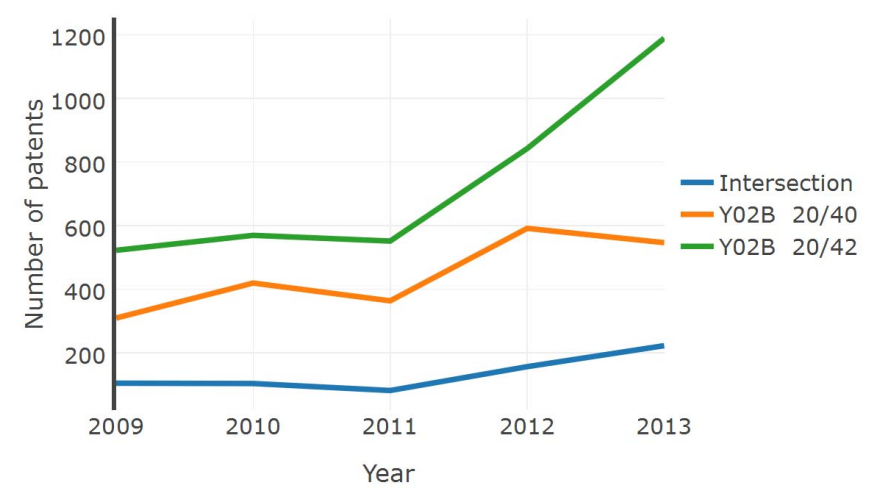

Figure 4 - Number of patents of Y02B 20/40, Y02B 20/42, and patents in their intersection 2009-2013.

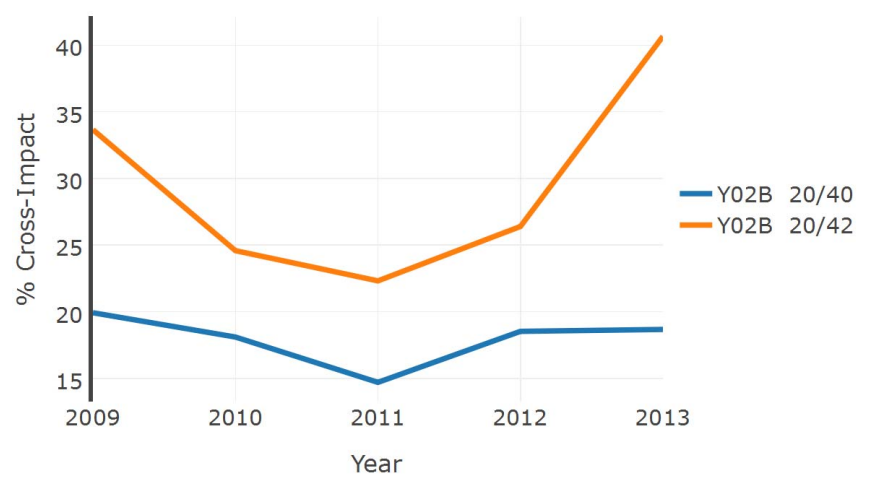

Figure 5 - Cross-impact between Y02B 20/40 and Y02B 20/42, 2009 -2013.

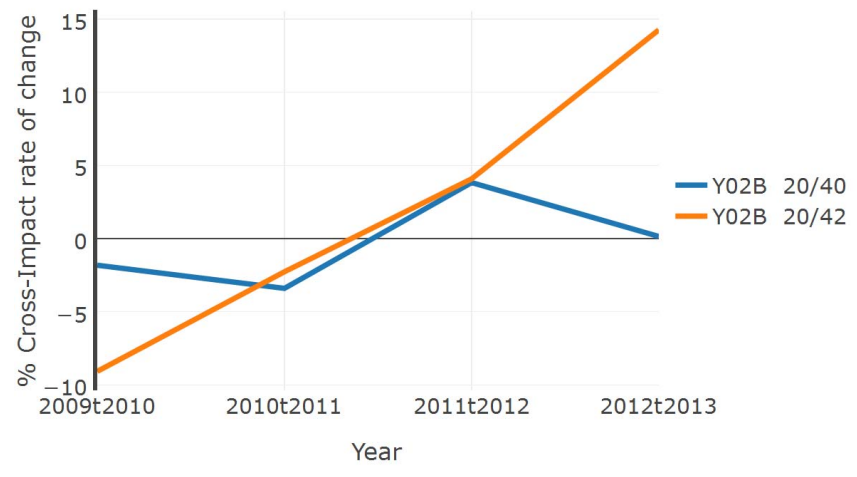

Figure 6 - Rate of change of cross-impact between Y02B 20/40 and Y02B 20/42, $2009-2013$.

Figure 5. shows the changes in cross-impact results. Red line illustrates trend of impact Y02B 20/42 had on Y02B $20 / 40$ and blue line shows the other way around. Figure 6. shows the rate of changes of cross-impact. The impact of Y02B 20/42 on Y02B 20/40 had rate of change with positive slope in which half of the trend line located in negative side and the other half in positive side. This implies that even if over a certain period the impact was declining, it was slowing down and then started to increase slightly faster. This result along with trend of growth for number of patents in Y02B 20/40 group and its intersection with Y02B 20/42 shows that the impact of Y02B 20/42 on Y02B 20/40 will increase in future.

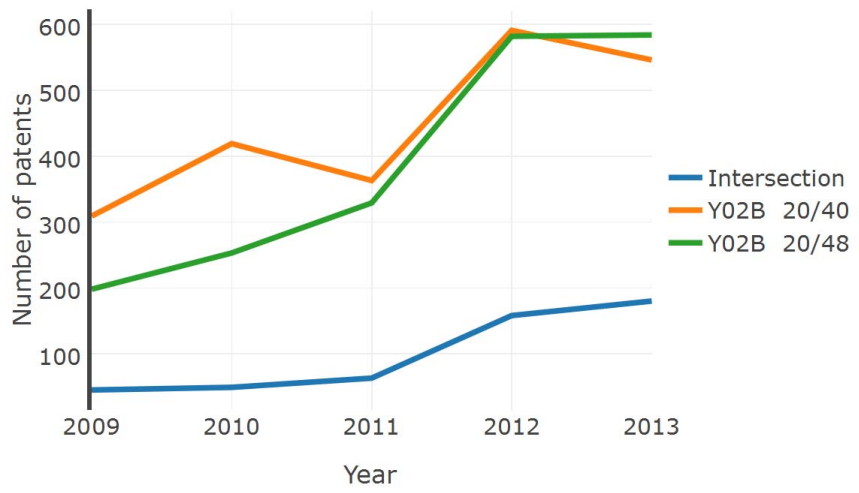

Figure 7 - Number of patents of Y02B 20/40, Y02B 20/48, and patents in their intersection 2009-2013.

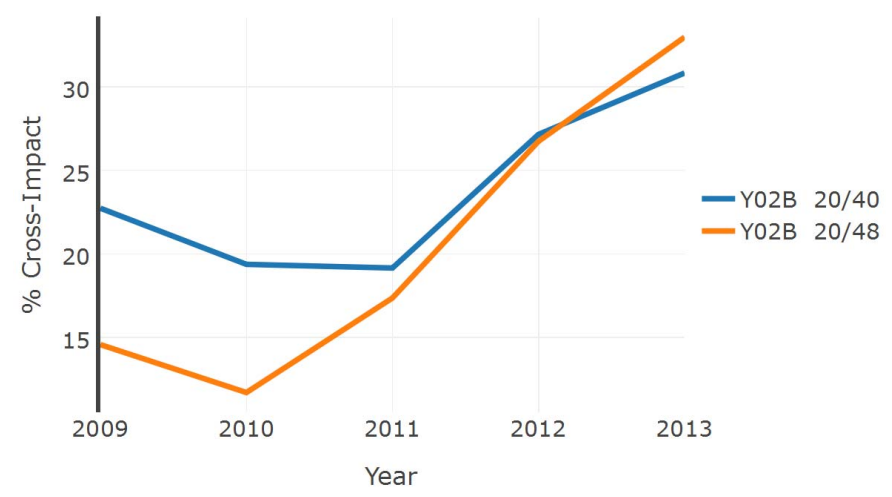

Figure 8 - Cross-impact between Y02B 20/40 and Y02B 20/48, 2009 -2013. 


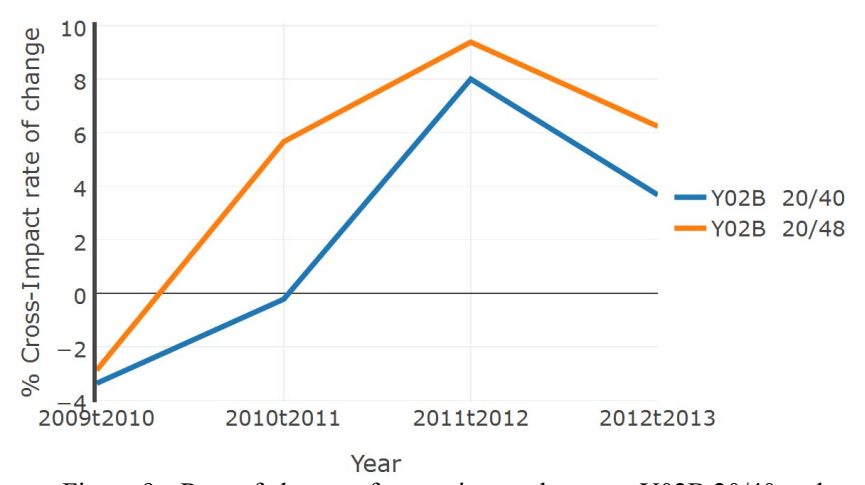

Figure 9 - Rate of change of cross-impact between Y02B 20/40 and Y02B 20/48, $2009-2013$.

Figure 7., Figure 8., and Figure 9. illustrate the trend of change in factors affecting convergence of Y02B 20/40 and Y02B 20/48 and their cross-impact rate. The impact that both CPC classes had on each other were growing since 2010, though, the impact of Y02B 20/48 on Y02B 20/40 were growing faster. Despite of the fact that growth of both impacts slowed down in 2013, impact of Y02B 20/48 on Y02B 20/40 surpassed the amount of impact Y02B 20/40 had on Y02B 20/48. It is expected that cross-impact between these two CPC groups grow similarly.

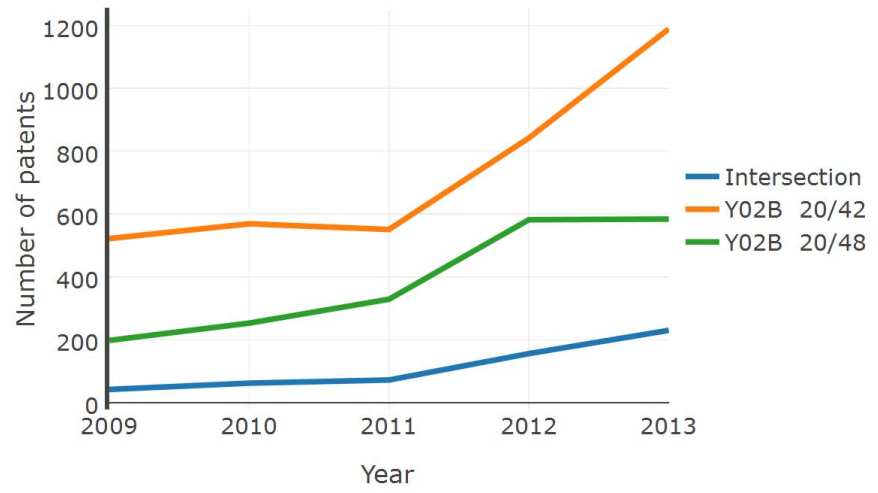

Figure 10 - Number of patents of Y02B 20/42, Y02B 20/48, and patents in their intersection 2009-2013.

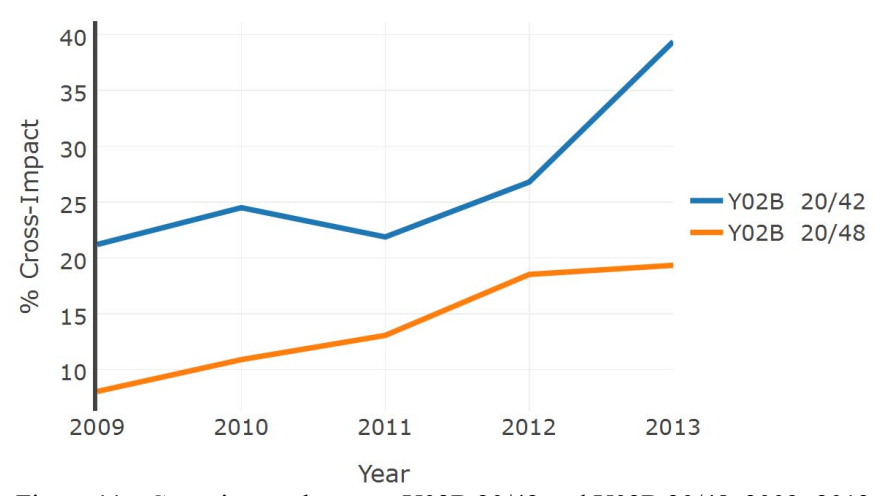

Figure 11 - Cross-impact between Y02B 20/42 and Y02B 20/48, 2009 -2013.

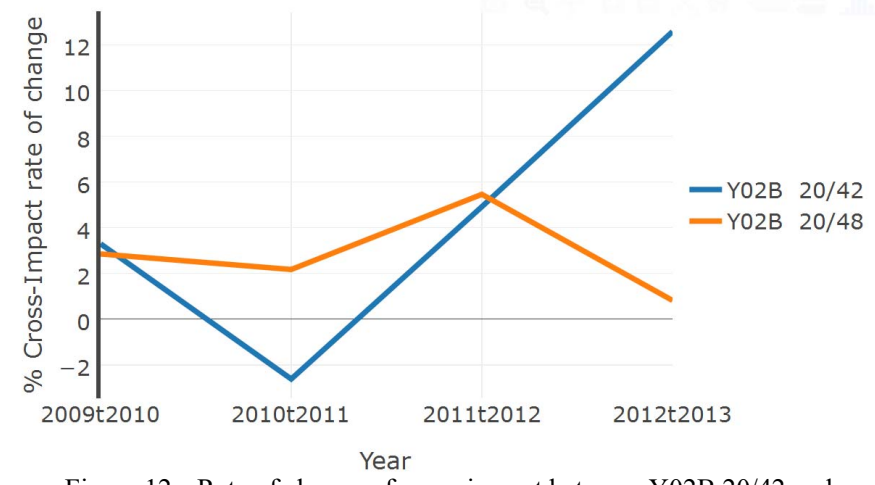

Figure 12 - Rate of change of cross-impact between Y02B 20/42 and Y02B 20/48, $2009-2013$.

The cross-impact analysis between Y02B 20/42 and Y02B 20/48 break down through Figure 10., Figure 11., and Figure 12. Though, both impact showed increasing pattern, impact of Y02B 20/48 on Y02B 20/42 increased faster than impact of Y02B 20/42 on Y02B 20/48. While impact of Y02B 20/48 on Y02B 20/42 were raising so fast, impact of Y02B 20/42 on Y02B 20/48 were increasing very slowly or staying flat. It is expected cross-impact holds the same pattern in future.

\section{CONCLUSION}

In recent years, there have been activities to converge various system with the lighting system to develop integrated lighting system. As part of these activities, we tried to study the convergence of controlling system which yields energy efficiency. Trend impact analysis monitors the convergence activities over a period of time to predict the future. The length of time required for each convergence study could differ from one case to the other. For instance, industry convergence intuitively takes more time than technology convergence. In some case - like ours - there are not enough data point, so we took a new approach to using scenario analysis to anticipate the convergence trend for a longer period of time, based on available data over a short period of time. We applied this new approach in the case of lighting controlling systems. Followings summarize the results.

As we discussed, focus on timing and scheduling strategy are higher than other strategies with overall 3673 granted patents over 5 years. There is more focus on timing and scheduling as well as smart controller strategy, and also techniques to control light source in recent years. Patents in these three areas are doubled or tripled over a given time, while, the number of patents for detection of users with or without controlling the access to promises and illumination level strategies are low and even decreased more since 2011.

From convergence perspective, detecting illumination level control strategy has least interaction with other strategies. It has least impacted by others and it has very low impact on others as well. Besides, though timing and scheduling strategy are developing almost independently, they have highest impact on other strategies. There is sizable chance to consider timing and scheduling strategy when developing other techniques and strategies. Furthermore, as anticipated the impact of timing and 
scheduling on smart controller strategy and controlling techniques will grow, on the other hand, the impact of later ones on timing and scheduling will either stays the same or slowly increases. However, smart controller strategy and controlling techniques show almost same increasing pattern since 2011 and the impact which they have on each other are equally increasing. Since, developing detection of users with or without controlling the access to promises and illumination level strategies received lower attention than other three CPC groups and there is small variation in the number of patents, it is expected that result stated in TABLE 3. be a good estimation for these three CPC groups convergence with others. (For more detailed analysis for these CPC groups visit https://ninach.shinyapps.io/Cross_impact_analysis/).

\section{REFERENCES}

[1] C.-S. Curran and J. Leker, "Patent indicators for monitoring convergence-examples from NFF and ICT," Technol. Forecast. Soc. Change, vol. 78, no. 2, pp. 256-273, 2011.

[2] F. Hacklin, C. Marxt, and F. Fahrni, "Coevolutionary cycles of convergence: An extrapolation from the ICT industry," Technol. Forecast. Soc. Change, vol. 76, no. 6, pp. 723-736, 2009.

[3] T. C. Weenen, B. Ramezanpour, E. S. Pronker, H. Commandeur, and E. Claassen, "Food-Pharma Convergence in Medical Nutrition-Best of Both Worlds?," PloS One, vol. 8, no. 12, p. e82609, 2013.

[4] N. Preschitschek, H. Niemann, M. G. Moehrle, and J. Leker, "Semantic analyses vs. IPC co-classification analyses of patents: Which one better serves to anticipate converging industries?," in 2012 Proceedings of PICMET'12: Technology Management for Emerging Technologies, 2012, pp. 566-578.

[5] J. Y. Choi, S. Jeong, and K. Kim, "A study on diffusion pattern of technology convergence: Patent analysis for Korea," Sustainability, vol. 7, no. 9, pp. 11546-11569, 2015.

[6] H. Lee and M. Choi, "Five year trends of ICT convergence based on KIPO issued patents," in 2012 International Conference on ICT Convergence (ICTC), 2012, pp. 622-626.

[7] S.-H. Hwang, "An analysis of industrial convergence coefficient using patent data in Korea," in Advanced Communication Technology (ICACT), 2013 15th International Conference on, 2013, pp. 391-394.

[8] B. Yoon and S. Lee, "Patent analysis for technology forecasting: Sectorspecific applications," in 2008 IEEE International Engineering Management Conference, 2008, pp. 1-5.

[9] Cisco, "Cisco Digital Ceiling (Whitepaper)," 2016. [Online]. Available: http://pages.orionlighting.com/rs/648-ATG-478/images/white-paperc11-736542.pdf.

[10] Z. Kerravala, "A Digital Ceiling Is Now a BUSINESS IMPERATIVE (whitepaper)," Aug-2016. [Online]. Available: https://www.cisco.com/c/dam/en/us/solutions/collateral/industrysolutions/cisco-digital-ceiling.pdf.

[11] Energy Star, "Energy Star Building Upgrade Manual Chapter 6: Lighting." [Online]. Available:
https://www.energystar.gov/sites/default/files/buildings/tools/EPA_BU M_CH6_Lighting.pdf. [Accessed: 10-Jul-2016].

[12] IEA, ECBCS, Annex 45, "GUIDEBOOK ON ENERGY EFFICIENT ELECTRIC LIGHTING FOR BUILDINGS." [Online]. Available: http://www.ecbcs.org/docs/ECBCS_Annex_45_Guidebook.pdf. [Accessed: 10-Jul-2016].

[13] D. Maniccia, B. Rutledge, M. S. Rea, and W. Morrow, "Occupant use of manual lighting controls in private offices," J. Illum. Eng. Soc., vol. 28, no. 2, pp. 42-56, 1999.

[14] J. D. Jennings, F. M. Rubinstein, D. DiBartolomeo, and S. L. Blanc, "Comparison of control options in private offices in an advanced lighting controls testbed," J. Illum. Eng. Soc., vol. 29, no. 2, pp. 39-60, 2000 .

[15] A. D. Galasiu, G. R. Newsham, C. Suvagau, and D. M. Sander, "Energy saving lighting control systems for open-plan offices: a field study," Leukos, vol. 4, no. 1, pp. 7-29, 2007.

[16] G. Newsham, C. Arsenault, J. Veitch, A. M. Tosco, and C. Duval, "Task lighting effects on office worker satisfaction and performance, and energy efficiency," Leukos, vol. 1, no. 4, pp. 7-26, 2005.

[17] J. Phelan, "Lighting Control Technology for Digital and Dynamic Luminaires," IES - San Francisco Section, 26-Jun-2014. [Online]. Available: http://www.iessf.net/archives/. [Accessed: 11-Jul-2016].

[18] L. Leydesdorff, F. Alkemade, G. Heimeriks, and R. Hoekstra, "Patents as instruments for exploring innovation dynamics: geographic and technological perspectives on 'photovoltaic cells," Scientometrics, vol. 102 , no. 1 , pp. 629-651, 2015.

[19] EPO, “Cooperative Patent Classification." [Online]. Available: https://worldwide.espacenet.com/classification?locale=en_EP\#!/CPC=/.

[20] Y.-L. Chen and Y.-C. Chang, "A three-phase method for patent classification," Inf. Process. Manag., vol. 48, no. 6, pp. 1017-1030, 2012.

[21] N. Preschitschek, H. Niemann, J. Leker, and M. G. Moehrle, "Anticipating industry convergence: semantic analyses vs IPC coclassification analyses of patents," Foresight, vol. 15, no. 6, pp. 446464, 2013.

[22] J.-T. Hwang and B.-K. Kim, "Analysis on the multi-technology capabilities of Korea and Taiwan using patent bibliometrics," Asian J. Technol. Innov., vol. 14, no. 2, pp. 183-199, 2006.

[23] C. Choi, S. Kim, and Y. Park, "A patent-based cross impact analysis for quantitative estimation of technological impact: The case of information and communication technology," Technol. Forecast. Soc. Change, vol. 74, no. 8, pp. 1296-1314, 2007.

\section{APPENDIX}

select tls201_appln.docdb_family_id, appln_auth, appln_nr, appln_kind, appln_filing_year, granted, nb_citing_docdb_fam, cpc_position, cpc_class_symbol from tls201_appln join tls224_appln_cpc on tls201_appln.appln_id = tls224_appln_cpc.appln_id

where

year(tls201_appln.appln_filing_date) $>=2009$

And year( tls201_appln.appln_filing_date) $<=2013$

And tls224_appln_cpc.cpc_class_symbol $={ }^{\prime} * '$

And tls201_appln.granted $=1$;

(*Y02B 20/40, Y02B 20/42, Y02B 20/44, Y02B 20/445, Y02B 20/46, Y02B 20/48) 